\title{
RESEARCH
}

Open Access

\section{Quality of referrals to a rheumatology service before and after implementation of a triage system with telemedicine support}

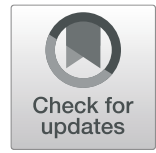

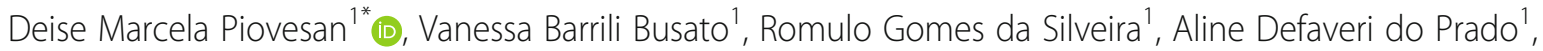
Cynthia Goulart Molina-Bastos²,3, Sheila Hickmann', Guilherme Kopik Bongiorno ', Camila de David Cruz', Sheron Zamboni ${ }^{1}$, Julio César Simon ${ }^{1}$, Marcelo Rodrigues Gonçalves ${ }^{2,3}$ and Markus Bredemeier ${ }^{1}$

\begin{abstract}
Purpose: To evaluate the quality of referrals for a first Rheumatology consultation at a tertiary care center in a southern Brazilian capital (Porto Alegre, RS), having as background findings from a similar survey performed in 2007/2008. Since then, our state has implemented referral protocols and a triage system with teleconsulting support exclusively for referrals from locations outside the capital, permitting a comparison between patients screened and not screened by the new system.
\end{abstract}

Methods: Physicians of the Rheumatology Service at Hospital Nossa Senhora da Conceição prospectively collected information regarding first visits over a 6-month period (Oct 2017 to March 2018). We recorded demographic characteristics, diagnostic hypotheses, date of referral, and the municipality of origin (within the state of Rio Grande do Sul). We considered adequate referrals from primary health care when a systemic autoimmune inflammatory disease (SIRD) was suspected at first evaluation by the attending rheumatologist.

Results: Three hundred fifty-seven patients/appointments were eligible for analysis (193 from the capital and 164 from small and medium towns). In 2007/2008, suspected SIRD occurred in 76/260 (29.2\%) and 73/222 (32.9\%) among patients from the capital and outside counties, respectively ( $P=0.387)$. In $2017 / 2018$, suspected SIRD occurred in 75/193 (38.9\%) and 111/164 (67.7\%) in patients from the capital and outside counties, respectively (difference: $28.8,95 \% \mathrm{Cl}: 19.0$ to $38.9, P<0.001$ ), indicating a marked improvement in referrals submitted to the new triage system.

Conclusion: The quality of Rheumatology referrals in our state improved over the 10-year interval under study, particularly among patients from locations submitted to referral protocols and teleconsulting support.

Keywords: Telemedicine, Referral, Waiting time, Access to care, Telerheumatology

\footnotetext{
* Correspondence: deise.piovesan@hotmail.com

'Rheumatology Service at Hospital Nossa Senhora da Conceição (HNSC), Grupo Hospitalar Nossa Senhora da Conceição (GHC), Avenida Francisco

Trein, 596, 3 Andar, Porto Alegre, Rio Grande do Sul, Brazil

Full list of author information is available at the end of the article
}

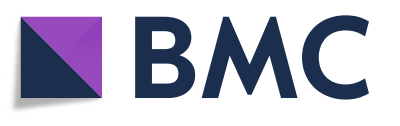

(c) The Author(s). 2021 Open Access This article is licensed under a Creative Commons Attribution 4.0 International License, which permits use, sharing, adaptation, distribution and reproduction in any medium or format, as long as you give appropriate credit to the original author(s) and the source, provide a link to the Creative Commons licence, and indicate if changes were made. The images or other third party material in this article are included in the article's Creative Commons licence, unless indicated otherwise in a credit line to the material. If material is not included in the article's Creative Commons licence and your intended use is not permitted by statutory regulation or exceeds the permitted use, you will need to obtain permission directly from the copyright holder. To view a copy of this licence, visit http://creativecommons.org/licenses/by/4.0/. 


\section{Introduction}

The long waiting time for consultations with specialists is one of the most significant limitations of the Brazilian public health system (Sistema Único de Saúde, SUS). The difference between supply and demand in Rheumatology consultations is leading to a long list of patients waiting for an appointment [1].

In rheumatic inflammatory diseases, the time from first symptoms to the initiation of treatment is one of the main factors related to prognosis [2]. Besides the personal impact caused by the delay in treatment, there is an economic burden associated with the morbidity of rheumatic diseases that the early initiation of the treatment could minimize [3]. In Brazil, rheumatic diseases are an important cause of public healthcare expenditures. The indirect cost for patients with rheumatoid arthritis was estimated at US\$2423.51 per patient per year [4]. Early access to care for patients with a systemic inflammatory rheumatic disease (SIRD) is a current challenge in Brazil as well as in developed countries [5].

Rheumatology tertiary care centers should prioritize care for patients with systemic inflammatory rheumatic diseases (SIRDs) instead of diseases manageable at the primary care level [6]. In a previous study, performed at our Rheumatology Clinic at Hospital Nossa Senhora da Conceição/Grupo Hospitalar Conceição (HNSC/GHC) in 2007-2008, we evaluated 487 referrals from the capital and outside counties of our state (Rio Grande do Sul) [1]. We observed that only approximately $30 \%$ of the patients referred to Rheumatology (from both origins) had SIRDs, and there was no adequate prioritization of severe or urgent cases. In 2016, a project of the Federal University of Rio Grande do Sul [UFRGS] introduced a telemedicine system (TelessaúdeRS/UFRGS) for referrals to Rheumatology in the State of Rio Grande do Sul, in partnership with the Brazilian Ministry of Health and the State Health Department [7]. However, this system was initially introduced only for referrals from outside counties, excluding those from the capital. This created the opportunity to observe the effect of telemedicine in the quality of referrals independently from other changes that could have influenced public healthcare over time, given that the only significant difference in the referral processes was the introduction of this telemedicine system. So, our aim in the present study is to evaluate the impact of telemedicine in the quality of referrals to Rheumatology tertiary care, comparing the cases from outsides counties (screened by the telemedicine system) and cases from the capital (unscreened cases), having as background the data collected in 2007/2008 [1], when there was no regulation of referrals at all.

\section{Material and methods}

We performed a cross-sectional study at the Rheumatology Service of (HNSC/GHC). The study was approved by the Ethics Committee of the HNSC and registered under the number 04529218.0.0000.5530 of the CAAE (Certificate of Presentation for Ethical Appreciation).

The TelessaúdeRS/UFRGS ${ }^{\text {тм }}$ project identified the most common rheumatic diseases referred for specialized medical consultations. Family physicians and rheumatologists created referral protocols for each of these conditions. The protocols, available for the primary care physicians, defined the minimal required information that must be provided in the referral document and the clinical criteria to ask for a specialized care appointment $[7,8]$. All requests for specialized care appointments are analyzed by the medical regulatory team, reviewing the adequacy of the request according to requirements of the protocol. After that, the medical regulatory team decides to authorize the referral or request additional information from the primary care provider. Whenever the team agrees with the necessity of referral to the Rheumatology specialist, they classify it according to the priority degree, also based on the protocol. When the request does not fulfill the criteria for referral, a telephone consultation (provided by TelessaúdeRS ${ }^{\mathrm{TM}}$ via a free telephone hotline) was indicated. Teleconsulting was given by a trained primary health care physician or the rheumatologist itself (both members of the Telessaú$\operatorname{deRS}^{\mathrm{rm}}$ staff). Anyhow, the rheumatologist was always available for consultation if necessary [7-9]. Once the use of the protocol was approved by the State Health Secretariat of Rio Grande do Sul, the regulatory process was applied to every new referral from outside counties. Besides that, the team also retrospectively revised the waiting list of patients from outside counties and applied the new system to these referrals [9]. This system was not applied to patients referred from the state capital during the period covered by this report.

For the present study, we collected data from patients scheduled for first Rheumatology consultations from October 01, 2017, to March 31, 2018. All patients attending first appointments and referred from primary health care (PHC) were considered eligible. Using a standard research protocol, we gathered the following data from the referral document elaborated at the PHC unit: the place of origin, date of referral from the PHC unit, and diagnostic hypotheses elaborated by the PHC physician. Further data collected during the consultation were attendance or not (in case of absenteeism), age, gender, diagnostic hypothesis formulated during the consultation by the rheumatologist (up to 3 could be recorded), urgency or not (we defined urgency if there was a risk of damage to a vital organ, rheumatoid arthritis with factors for worse prognosis or pregnancy), and the date of 
the consultation. If the date of referral was not reported on the PHC document, we asked the patient to choose a date according to his recall of the moment of referral. In rare cases, it was necessary to contact patients afterward by telephone or review medical records to clarify uncertain information. For analytical purposes, when the rheumatologist suspected any systemic inflammatory rheumatic disease (SIRD) during the first visit, the referral was considered adequate. The diseases classified as SIRD were rheumatoid arthritis, systemic lupus erythematosus, Sjögren's syndrome, systemic sclerosis, inflammatory myopathies, undifferentiated or overlapping autoimmune connective tissue diseases, spondyloarthritis (including ankylosing spondylitis, psoriatic arthritis, arthritis associated with inflammatory bowel disease, reactive arthritis, and undifferentiated spondyloarthritis), polymyalgia rheumatica, antiphospholipid syndrome, systemic vasculitis, and other less common autoimmune disorders (e.g., sarcoidosis, remitting seronegative symmetrical synovitis with pitting edema, and relapsing polychondritis). The research protocol and all study procedures were almost identical to those employed in our 2007/2008 study [1], making the results easily comparable.

\section{Statistical analysis}

Statistical analyses were performed using SPSS for Windows, version 20.0 (IBM Corporation, Armonk, NY, USA). Quantitative variables were graphically and statistically tested (with the Kolmogorov-Smirnov goodnessof-fit test) for normality of distribution. We describe categorical variables as numbers and percentages and tested associations using Pearson's chi-square test. Homogeneity of $2 \times 2$ tables across strata was evaluated with Woolf's test. We presented variables with a normal distribution as mean \pm standard deviation (SD). We presented non-normal quantitative or ordinal variables as median and the 25th and 75th percentiles and performed between-group comparisons using the Mann-
Whitney test. Two-tailed $P$ values less than or equal to 0.05 were considered statistically significant.

\section{Results}

There were 500 Rheumatology first consultations schedules during the study period. Of these, 71 were already being treated in the Rheumatology unit; therefore, they were not considered first-time Rheumatology visits (these consultations were scheduled as first visits only for bureaucratic reasons). Of the remaining appointments, 72 did not attend, and 357 patients remained available for analysis; the characteristics of these patients are described in Table 1. Suspected SIRD by the rheumatologist occurred in approximately half of the cases. The date of referral was not reported in the official referral document of only 23 patients (6.4\%). The mean \pm SD waiting time was $10.5 \pm 7.8$ months.

Table 2 shows diagnostic hypotheses formulated by the PHC doctors. The most frequent hypothesis was rheumatoid arthritis (RA, 27.5\%), followed by systemic lupus erythematosus (SLE, 15.4\%). Referrals for suspected osteoarthritis and fibromyalgia, which generally do not require secondary or tertiary care, occurred in 5.0 and $4.5 \%$ of cases, respectively. Table 3 shows the most frequent diagnosis ascertained or suspected in the first consultations by the rheumatologist. RA was the main hypothesis in $20.4 \%$ of cases, followed by osteoarthritis (17.4\%) and fibromyalgia (16.8\%). SLE was suspected in $11.5 \%$ of the cases.

Table 4 describes the waiting time for rheumatologic consultation in the $2017 / 2018$ and the 2007/2008 surveys. Comparing both surveys, there is a significant increase in the waiting time for rheumatologic consultation over the 10 years period under study.

Table 5 compares prevalence of suspected SIRD and urgent cases obtained in 2007/2008 with those observed in the present study (2017/2018). In general, the prevalence of suspected SIRD raised from approximately 30\% in $2007 / 2008$ to more than $50 \%$ in $2017 / 2018$. In $2007 /$

Table 1 Demographic characteristics of eligible patients (total of 357 patients)

\begin{tabular}{lc}
\hline Female $-\mathrm{n}(\%)$ & $305(85.4)$ \\
Age (years) - mean \pm SD, range of values & $53.0 \pm 14.9,13$ to 85 \\
Origin: & $193(54.1 \%)$ \\
$\quad$ Porto Alegre (capital) $-\mathrm{n}(\%)$ & $164(45.9 \%)$ \\
$\quad$ Outside counties within the same state $-\mathrm{n}(\%)$ & $12.1(4.4-14.1), 0.23$ to 63.8 \\
Waiting time (months) - median (P25 - P75), range of values & $78(21.8)$ \\
Urgent need for an appointment (according to rheumatologist) - $\mathrm{n}(\%)$ & $220(61.6)$ \\
Suspected SIRD according to the general practitioner- $\mathrm{n}(\%)$ & $186(52.1)$ \\
Suspected SIRD according to the rheumatologist $-\mathrm{n}(\%)$ & $334(93.6)$ \\
Referral date (obtained from the referencing document) - $\mathrm{n}(\%)$ &
\end{tabular}

SD standard deviation; $P 25$ 25th percentile; $P 75$ 75th percentile; SIRD systemic inflammatory rheumatic disease 
Table 2 Frequency of diagnoses formulated by the general practitioner to justify referral $(n=357)$

\begin{tabular}{ll}
\hline Rheumatoid arthritis & $98(27.5 \%)$ \\
Systemic lupus erythematosus & $55(15.4 \%)$ \\
Undifferentiated arthralgia & $41(11.5 \%)$ \\
Unspecified inflammatory disease & $23(6.4 \%)$ \\
Osteoarthritis & $18(5.0 \%)$ \\
Fibromyalgia & $16(4.5 \%)$ \\
Psoriatic arthritis & $15(4.2 \%)$ \\
Ankylosing spondylitis & $15(4.2 \%)$ \\
Sjögren's syndrome & $9(2.5 \%)$ \\
Non-specific rheumatism & $9(2.5 \%)$ \\
Gout & $6(1.7 \%)$ \\
Systemic sclerosis & $5(1.4 \%)$ \\
Laboratory abnormalities & $4(1.1 \%)$ \\
Other diseases & $43(12.0 \%)$ \\
\hline
\end{tabular}

2008, the proportion of patients with a SIRD was similar in outside counties (32.9\%) and in the capital (29.2\%), as well as the frequency of urgent cases (44.7 and 42.3\%, respectively). In 2017/2018, however, the prevalence of SIRDs was significantly higher in patients from interior towns $(67.7 \%)$ comparing to those from the capital

Table 3 Diagnostic hypotheses formulated by the rheumatologist at first consultations $(n=357)$

\begin{tabular}{ll}
\hline Rheumatoid arthritis & $73(20.4 \%)$ \\
Osteoarthritis & $62(17.4 \%)$ \\
Fibromyalgia & $60(16.8 \%)$ \\
Systemic lupus erythematosus & $41(11.5 \%)$ \\
Spondyloarthritis & $18(5.0 \%)$ \\
Psoriatic arthritis & $15(4.2 \%)$ \\
Periarthritis & $14(3.9 \%)$ \\
Sjögren's Syndrome & $10(2.8 \%)$ \\
Gout & $9(2.5 \%)$ \\
Systemic sclerosis & $5(1.4 \%)$ \\
Systemic vasculitis & $5(1.4 \%)$ \\
Osteoporosis & $5(1.4 \%)$ \\
Juvenile idiopathic arthritis & $4(1.1 \%)$ \\
Uveitis & $4(1.1 \%)$ \\
Low back pain & $3(0.8 \%)$ \\
Behçet's disease & $2(0.6 \%)$ \\
Anti-phospholipid syndrome & $2(0.6 \%)$ \\
Sarcoidosis & $2(0.6 \%)$ \\
Dermato- or polymyositis & $2(0.6 \%)$ \\
Eosinophilic fasciitis & $1(0.3 \%)$ \\
Other diseases & $20(5.6 \%)$ \\
\hline
\end{tabular}

(38.9\%) (difference in prevalence, 28.8, 95\% CI, 18.1 to $38.9 \%, P<0.001$ ), suggesting a positive impact of the triage system in the quality of referrals. In the same direction, in 2017/2018, urgent cases represented $29.9 \%$ of cases from outside counties versus $15.0 \%$ of cases from the capital (difference in prevalence, 14.9, 95\% CI, 5.7 to 23.3\%, $P=0.001)$.

\section{Discussion}

In this cross-sectional study, we observed a significant improvement in the quality of referrals to Rheumatology consultations in the state of Rio Grande do Sul over 10 years. Comparing the results of the 2007/2008 survey with those observed in the present study (2017/2018), we noticed more cases suspected of SIRDs in the latter (52.1\%, versus $30.9 \%$ in the former). However, we found that the increase in the proportion of SIRDs was more marked in outside counties' referrals (from 33 to 68\%) compared to referrals from the capital (from 29 to 39\%) over these 10 years. This change may be explained partly by a general improvement in knowledge of the rheumatic diseases among PHC physicians. However, the more marked increase in the proportion of adequate referrals from outside counties suggest that much of this improvement is related to the application of the triage program and teleconsulting support system [7-9].

Previous studies had already demonstrated the benefits of referral screening processes for referrals to specialized care $[5,10]$. In a Canadian study similar to ours, the implantation of triage for referrals promoted a reduction in waiting time for patients with suspected inflammatory arthritis (IA) and connective tissue diseases (CTD). In contrast, the waiting time for those with suspected nonIA and non-CTD increased [11]. Teleconsulting support seems to work as a continued medical education process, leading to reduced referrals to specialties and improving the quality of referrals [12]. In our country, Meyama et al. evaluated the impact of teleconsulting in referrals in Santa Catarina (another Southern Brazilian state). They found a decrease of more than $50 \%$ in new solicitations of Rheumatology referrals after starting a mandatory teleconsulting program [12].

Interestingly, we observed a reduction in cases classified as urgent in $2017 / 2018$ compared to the $2007 / 2008$ survey. A difference in the classification methodology can probably explain this finding. In 2007/2008, cases were classified as urgent based on subjective rheumatologist's evaluation without following clear pre-specified criteria. However, in the present survey, we used stricter criteria (pregnancy, risk of vital organ damage, and RA with poor prognosis) to define an urgent case.

We noticed that the waiting time for consultation increased considerably during the time frame encompassed by this study. A possible explanation for this 
Table 4 Comparison of waiting time (months) of patients referred for first Rheumatology consultations in $2007 / 2008$ (482 patients) and 2017/2018 (357 patients)

\begin{tabular}{lll}
\hline & Mean \pm SD & Median (P25-P75), range of values \\
\hline $\mathbf{2 0 0 7 / 2 0 0 8}$ & $7.8 \pm 11.1$ & $3.8(1.5-10.0), 0.1$ to 96.0 \\
$\mathbf{2 0 1 7 / 2 0 1 8}$ & $10.5 \pm 7.8$ & $12.1(4.4-14.1), 0.2$ to 63.8 \\
\hline
\end{tabular}

* Mann-Whitney test. SD standard deviation; P25 25th percentile; $P 75$ 75th percentile

observation is that we collected the data from October 01, 2017, to March 31, 2018, just a year and a half after the changes in the referral system. Given that data from TelessaúdeRS/UFRGS ${ }^{\mathrm{m}}$ shows a decrease in about $30 \%$ of referrals after the triage system with protocols was implemented [9], it is likely that the waiting time of our 2017/2018 sample reflects patients already waiting for a long time for a rheumatology consultation before the implementation of the system. To illustrate that, when Telessaúde started the process, there were more than 7000 cases on the waiting list for Rheumatology appointments (unpublished data). Advances in the treatment of rheumatic diseases and the knowledge of the importance of early treatment to obtain better outcomes may also have stimulated a larger number of referrals, increasing the waiting list, and consequently, the waiting time.

There was a significant disparity in the suspicion of fibromyalgia and osteoarthritis among primary care physicians and rheumatologists in the present study. Of the 357 patients referred, only $9.5 \%$ (34 patients) had one of these diseases as an initial suspicion by the primary care physician (the screening system accepted these cases, according to the protocol, because they were considered refractory to management in primary care or the diagnosis was doubtful). On the other hand, one of these two diseases was the first hypothesis in 122 patients (34.2\%) at the first rheumatology visit. Cases of fibromyalgia and osteoarthritis can usually be managed at the primary care level [6]. The low prevalence of SIRDs and the high frequency of musculoskeletal symptoms in the general population represent a challenge to the general practitioner to identify such patients timely. Equipping him with the necessary knowledge to recognize these patients more safely is crucial for improving the referral process [13]. Measures such as lectures, discussion with the rheumatologist, and educational material are strategies that have already demonstrated benefits on the quality and quantity of referrals [5].

The present study has several strengths. There are no similar studies evaluating referral from primary care to Rheumatology and the impact of applying referral protocols with telemedicine support in our environment. The high number of first consultation visits (the largest in the state of Rio Grande do Sul at that time, compared to other tertiary care centers) in our service allowed us to obtain a significant and representative number of individuals from different origins for the analysis.

Our study also has limitations. The observational design of our research has well-known limitations in comparison to experimental studies. So,we cannot absolutely affirm that the improvement in referral quality is explained only by changes in the referral process. Another limitation is that we did not assess the effects of the different components of the referral process (triage with protocol and teleconsulting) independently. For analytical purposes, we considered as appropriate only referrals suspected of SIRDs. We know that some patients with other diseases (such as gout, osteoarthritis, and

Table 5 Comparison of features of patients referred to first Rheumatology consultations in 2007/2008 (482 patients) and 2017/2018 (357 patients)

\begin{tabular}{|c|c|c|c|c|}
\hline & Porto Alegre (Capital) & Outside Counties & $P$ Value* & $P$ value of homogeneity test ${ }^{* *}$ \\
\hline Hometown & & & & - \\
\hline 2007/2008 - n (\%) & $260(53.9)$ & $222(46.1)$ & - & \\
\hline 2017/2018 - n (\%) & $193(54.1)$ & $164(45.9)$ & - & \\
\hline Urgent cases & & & & 0.016 \\
\hline 2007/2008 - n (\%) & $110 / 260(42.3)$ & 98/219 (44.7)† & 0.591 & \\
\hline $2017 / 2018-n(\%)$ & 29/193 (15.0) & 49/164 (29.9) & 0.001 & \\
\hline \multicolumn{4}{|c|}{ Systemic inflammatory rheumatic diseases } & $<0.001$ \\
\hline 2007/2008 - n (\%) & $76 / 260(29.2)$ & $73 / 222(32.9)$ & 0.387 & \\
\hline $2017 / 2018$ - n (\%) & 75/193 (38.9) & $111 / 164(67.7)$ & $<0.001$ & \\
\hline
\end{tabular}

*Pearson qui-square test comparing capital and outside counties. ${ }^{* *}$ Woolf's test for homogeneity of $2 \times 2$ tables across strata; a statistically significant difference indicates heterogeneity. +For 3 cases, information on urgency was missing 
fibromyalgia) may sometimes require specialized diagnostic evaluation and treatment, particularly in refractory cases. Even so, the increased proportion of SIRDs among referred patients represents greater adequacy in the referral process, as these patients could hardly be adequately treated at the primary level of care. In such cases, intravenous infusions, immunosuppressants, and specialized tests available only in more advanced levels of care are often required. We based the diagnosis of a SIRD on the first clinical evaluation by the rheumatologist and previous medical exams brought by the patients. Therefore, some initial diagnoses may have changed during medical follow-up. Another potential limitation is that we analyzed only patients referred to the HNSC/ GHC Rheumatology Service, not including patients referred to other services. However, considering that the schedule of appointments for different Rheumatology services occurs in a centralized and non-regionalized manner and the large number of patients received by our service, our sample can be considered representative of referrals to Rheumatology in our state.

\section{Conclusions}

Considering the present results, we conclude that the quality of referrals to specialist consultation in Rheumatology improved in our state over 10 years. Most of this progress can probably be attributed to applying the triage system with protocols and telemedicine support. However, further changes are still necessary to reduce the waiting time for consultations and attain higher referral quality. Continuous and coordinated efforts among rheumatologists, general practitioners, and health managers are needed to optimize access to rheumatologic assistance.

\section{Acknowledgments}

We thank Elise Botteselle Oliveira (Teleconsulting Team Coordinator) and Rudi Roman (Referral Program Team Coordinator) from TelessaudeRS for their invaluable assistance.

\section{Authors' contributions}

DMP worked on the conception, analysis, and interpretation of data, drafting the article and approval of the version to be published. VBB worked on the conception, data collecting, analysis, and approval of the version to be published. RGS worked on the conception, data collecting, analysis, and approval of the version to be published. ADP worked on the conception, drafting the article, and approval the version to be published. CGMB worked on interpreting data, drafting the article, and approval the version to be published. SH worked conception, data collecting, and approval of the version to be published. GKB worked on the conception, data collecting, and approval of the version to be published. CDC worked on the conception, data collecting, and approval of the version to be published. SZ worked on the conception, data collecting, and approval of the version to be published. JCS worked on conception, data collecting, and approval of the version to be published. MR worked on the interpretation of data, drafting the article, and approval of the version to be published. MB worked on the conception, analysis, and interpretation of data, preparing the article and approval of the version to be published.
Funding

No funding was received for this study.

\section{Availability of data and materials}

The datasets used and analyzed during the current study are available from the corresponding author upon reasonable request.

\section{Declarations}

\section{Ethics approval and consent to participate}

The study was approved by the Ethics Committee of the HNSC and registered under the number 04529218.0.0000.5530 of the CAAE (Certificate of Presentation for Ethical Appreciation).

\section{Consent for publication}

Confidentiality was guaranteed, and there was no intervention or change in the care assistance motivated by the research, so informed consent was not mandatory.

\section{Competing interests}

All authors declare that they have no conflicts of interest.

\section{Author details}

${ }^{1}$ Rheumatology Service at Hospital Nossa Senhora da Conceição (HNSC), Grupo Hospitalar Nossa Senhora da Conceição (GHC), Avenida Francisco Trein, 596, 3 Andar, Porto Alegre, Rio Grande do Sul, Brazil. ${ }^{2}$ Federal University of Rio Grande do Sul (UFRGS), Porto Alegre, Rio Grande do Sul, Brazil. ${ }^{3}$ TelessaúdeRS, Federal University of Rio Grande do Sul (UFRGS), Porto Alegre, Rio Grande do Sul, Brazil.

Received: 16 February 2021 Accepted: 25 June 2021

Published online: 20 July 2021

\section{References}

1. Simon JS, Maltichk M, da Silva EE, Lima VRB, Bredemeier M. Evaluation of the waiting time for rheumatology consultations at a tertiary care center of Porto Alegre - RS. Rev AMRIGS. 2008;52(4):303-8.

2. Hyrich KL. Patients with suspected rheumatoid arthritis should be referred early to rheumatology. BMJ. 2008;336(7637):215-6. https://doi.org/10.1136/ bmj.39381.597454.AE.

3. Cross M, Smith E, Hoy D, Carmona L, Wolfe F, Vos T, et al. The global burden of rheumatoid arthritis: estimates from the global burden of disease 2010 study. Ann Rheum Dis. 2014;73(7):1316-22. https://doi.org/10.1136/a nnrheumdis-2013-204627.

4. de Azevedo ABC, Ferraz MB, Ciconelli RM. Indirect costs of rheumatoid arthritis in Brazil. Value Health J Int Soc Pharmacoeconomics Outcomes Res. 2008;11(5):869-77. https://doi.org/10.1111/j.1524-4733.2008.00332.x.

5. Villeneuve E, Nam JL, Bell MJ, Deighton CM, Felson DT, Hazes JM, et al. A systematic literature review of strategies promoting early referral and reducing delays in the diagnosis and management of inflammatory arthritis. Ann Rheum Dis. 2013;72(1):13-22. https://doi.org/10.1136/annrheumdis-2 011-201063.

6. Hosie GAC. Series on education: teaching rheumatology in primary care. Ann Rheum Dis. 2000;59(7):500-3. https://doi.org/10.1136/ard.59.7.500.

7. Gonçalves MR, Umpierre RN, D'Avila OP, et al. Expanding primary care access: a telehealth success story. Ann Fam Med. 2017;15(4):383. https://doi. org/10.1370/afm.2086.

8. Deise Marcela Piovesan, Dimitris RucksVarvakiRados, Elise Botteselle de Oliveira, et al. Reference protocols for adult rheumatology. Published online 2017. https://www.ufrgs.br/telessauders/documentos/protocolos_resumos/ protocolo_ses_reumatologia_20170911_v015_cvc.pdf.

9. Katz N, Roman R, Rados DV, Oliveira EB, Schmitz CAA, Gonçalves MR, et al. Access and regulation of specialized care in Rio Grande do Sul: the RegulaSUS strategy of TelessaúdeRS-UFRGS. CiencSaude Coletiva. 2020;25(4): 1389-400. https://doi.org/10.1590/1413-81232020254.28942019.

10. Bignell $K$, Bender $C$, Lichtenstein $A$, et al. Improving access in rheumatology: evaluating the validity of a paper triage process involving an advanced practice physiotherapist through a retrospective chart review. Physiother Theory Pract. 2020;36(1):203-10. https://doi. org/10.1080/09593985.2018.1482978. 
11. Farrer C, Abraham L, Jerome D, Hochman J, Gakhal N. Triage of rheumatology referrals facilitates wait time benchmarks. J Rheumatol. 2016; 43(11):2064-7. https://doi.org/10.3899/jheum.151235.

12. Maeyama MA, Calvo MCM. Integration of telehealth in regulation centers: teleconsulting as a mediator between primary care and specialized care. Rev Bras Educ Médica. 2018;42(2):63-72. https://doi.org/10.1590/1981-52712 015v42n2rb20170125.

13. Mallen CD, Helliwell T, Scott IC. How can primary care physicians enhance the early diagnosis of rheumatic diseases? Expert Rev Clin Immunol. 2018; 14(3):171-3. https://doi.org/10.1080/1744666X.2018.1429919.

\section{Publisher's Note}

Springer Nature remains neutral with regard to jurisdictional claims in published maps and institutional affiliations.

Ready to submit your research? Choose BMC and benefit from:

- fast, convenient online submission

- thorough peer review by experienced researchers in your field

- rapid publication on acceptance

- support for research data, including large and complex data types

- gold Open Access which fosters wider collaboration and increased citations

- maximum visibility for your research: over $100 \mathrm{M}$ website views per year

At BMC, research is always in progress.

Learn more biomedcentral.com/submissions 